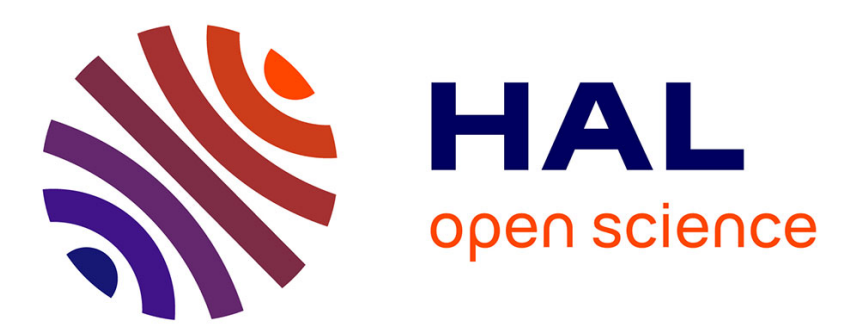

\title{
Microstructure of Powellite-Rich Glass-Ceramics: A Model System for High Level Waste Immobilization
}

\author{
T Taurines, B Boizot
}

\section{To cite this version:}

T Taurines, B Boizot. Microstructure of Powellite-Rich Glass-Ceramics: A Model System for High Level Waste Immobilization. Journal of the American Ceramic Society, 2012, 95 (3), pp.1-7. 10.1111/j.1551-2916.2011.05015.x . cea-01120954

\section{HAL Id: cea-01120954 https://hal-cea.archives-ouvertes.fr/cea-01120954}

Submitted on 27 Feb 2015

HAL is a multi-disciplinary open access archive for the deposit and dissemination of scientific research documents, whether they are published or not. The documents may come from teaching and research institutions in France or abroad, or from public or private research centers.
L'archive ouverte pluridisciplinaire HAL, est destinée au dépôt et à la diffusion de documents scientifiques de niveau recherche, publiés ou non, émanant des établissements d'enseignement et de recherche français ou étrangers, des laboratoires publics ou privés. 


\title{
Microstructure of powellite-rich glass-ceramics: a model system for high level waste immobilization
}

\author{
T. Taurines, B. Boizot
}

Laboratoire des Solides Irradiés, UMR 7642 CEA-CNRS-Ecole Polytechnique, 91128

Palaiseau, France

\begin{abstract}
In this study, we synthesized glass-ceramics from glasses in the system $\mathrm{SiO}_{2}-\mathrm{B}_{2} \mathrm{O}_{3}-\mathrm{Na}_{2} \mathrm{O}$ $\mathrm{CaO}-\mathrm{Al}_{2} \mathrm{O}_{3}-\mathrm{MoO}_{3}-\mathrm{Gd}_{2} \mathrm{O}_{3}$ by various heat treatments. Glass-ceramics contain only one crystalline phase in the bulk: powellite (namely $\mathrm{CaMoO}_{4}$ ). The influence of molybdenum and rare earth contents was studied by SEM and XRD. Heat treatments were optimized to lead to a wide range in size and concentration of powellite. Moreover, the molybdenum content left in residual glasses, calculated by XRD quantification, showed that the residual glasses have a similar composition for a given $\mathrm{Gd}_{2} \mathrm{O}_{3}$ content after heat treatments. This work has permitted to synthesize two phase glass-ceramics with constant borosilicate glass matrices and powellite crystals with controlled sizes and concentrations.
\end{abstract}

\section{Introduction}

Vitrification is a worldwide process used to immobilize high and long-lived radionucleii. Up to now, glasses are the most employed matrices as they have demonstrated their durability in respect to self-irradiation damages [1] and corrosion in repository conditions $[2,3]$. New materials have been studied in the last decade for specific purposes, like increasing the waste loading or increasing the amount of poor soluble elements like Mo and rare earth elements. Ceramics, like apatites or zirconolite [4, 5], were studied for specific elements immobilization. Despite very good immobilization properties, no industrial applications were developed due to the high pressures needed for fabrication and segregation processes at grain boundaries. New systems considered for nuclear waste applications are glass-ceramics, since they combine the advantages of glass fabrication and the good immobilization properties of ceramics [6]. Glass-ceramics can be obtained by appropriate compositions and/or heat treatments to favor crystallization.

Molybdenum is a non radioactive fission product found in high level nuclear waste, which can lead to a phase separation during melt cooling. The separated phase, called "yellow 
phase", can carry radioactive elements like ${ }^{137} \mathrm{Cs}$ and has to be avoided for durability reasons. Molybdenum is usually found as $\mathrm{Mo}^{6+}$ in glasses with a low solubility (around $1 \mathrm{~mol} \%$ ), which depends on the glass composition. In alumino borosilicate glasses, molybdenum usually crystallizes into $\mathrm{CaMoO}_{4}$ (namely powellite) or $\mathrm{Na}_{2} \mathrm{MoO}_{4}$ phases, which can incorporate rare earth elements [7]. For chemical durability reasons sodium molybdates crystallization has to be avoided. To favor $\mathrm{CaMoO}_{4}$ crystallization, various parameters play a key role. First, the cooling rate of the melt has a strong influence on the composition and on the morphology of the crystallized phases $[8,9]$. Moreover, the chemical composition of the glass also monitors the ratio between the phases $\mathrm{CaMoO}_{4}$ and $\mathrm{Na}_{2} \mathrm{MoO}_{4}$. In particular, the calcium and the boron contents have an important role on powellite crystallization [10].Recent studies also showed that the rare earth content plays a key role on molybdenum solubility in glass [8], and therefore on powellite crystallization. Increasing, the rare earth content can also increase the Mo solubility.

Several studies were conducted on simplified nuclear glasses with various irradiation processes like swift heavy ions [11], doping with radioelements [1] or electron irradiation [12]. As far as electron irradiation is concerned, different works have shown significant structural changes in borosilicate glasses at integrated doses around $10^{9} \mathrm{~Gy}$. In addition to punctual defects creation processes, an increase of glass polymerization associated to molecular oxygen production is observed $[13,14]$. These structural changes are explained by alkali migration under ionizing radiation [12]. However, to our knowledge, few studies have dealt with the influence of crystalline phases on the borosilicate glass matrix structural changes under ionizing radiation. In particular, different parameters like crystalline phase grains size (surface/volume ratio) and diffusion processes between glass and crystalline phases could influence alkali migration under ionizing radiation. All these parameters could strongly influence the irradiation damages in a glass ceramic system. It is therefore very important to study two phase model materials with controlled grain size and concentration in order to understand the structural changes under ionizing radiation.

For that purpose, we synthesized molybdenum enriched aluminoborosilicate glasses to study the $\mathrm{CaMoO}_{4}$ crystallization and to obtain a simplified model for powellite-rich glassceramics. Heat treatments were performed to control the size and the distribution of powellite crystals. Crystallized phases in the bulk and on the surface were studied by X-ray diffraction (XRD). Crystals size distributions and morphologies were studied by scanning electron microscopy (SEM). 


\section{Experimental methods}

\section{Glass-ceramics preparation}

For this study, we prepared glasses in the system: $\mathrm{SiO}_{2}-\mathrm{B}_{2} \mathrm{O}_{3}-\mathrm{Na} \mathrm{N}_{2} \mathrm{O}-\mathrm{CaO}-\mathrm{Al}_{2} \mathrm{O}_{3}$. Increasing amounts of $\mathrm{MoO}_{3}$ are added, from 0.5 to $4.5 \mathrm{~mol} \%$ in order to have a wide range in powellite concentration in the glass-ceramics. $\mathrm{Gd}_{2} \mathrm{O}_{3}$ is added at two contents, at low content $(0.15 \mathrm{~mol} \%), \mathrm{Gd}_{2} \mathrm{O}_{3}$ is used as a spectroscopic probe and at high content $(1 \mathrm{~mol} \%)$ is also used as a trivalent minor actinide surrogate.

(i) Serie $\mathrm{Mxg}:(0.9985-2 \mathrm{x} / 100)\left(61.16 \mathrm{SiO}_{2}-16.28 \mathrm{~B}_{2} \mathrm{O}_{3}-12.85 \mathrm{Na}_{2} \mathrm{O}-3.88 \mathrm{Al}_{2} \mathrm{O}_{3}-\right.$ 5.82CaO) $-\mathrm{x} \mathrm{CaO}-\mathrm{x} \mathrm{MoO}_{3}-0.15 \mathrm{Gd}_{2} \mathrm{O}_{3}$ (in mol\%) with $\mathrm{x}=0$, 0.5, 1.5, 2.5, 3.5 and 4.5.

(ii) Serie Mxg1 : Mxg1 (0.99-2x/100)(61.16 $\mathrm{SiO}_{2}-16.28 \mathrm{~B}_{2} \mathrm{O}_{3}-12.85 \mathrm{Na}_{2} \mathrm{O}-3.88 \mathrm{Al}_{2} \mathrm{O}_{3}$ - 5.82CaO) - $\mathrm{x} \mathrm{CaO}-\mathrm{x} \mathrm{MoO}_{3}-1 \mathrm{Gd}_{2} \mathrm{O}_{3}$ (in mol\%) with $\mathrm{x}=0,0.5,1.5,2.5,3.5$ and 4.5.

In the two series, $\mathrm{CaO}$ oxide was added in increasing amounts to the based glass composition to compensate the loss during powellite crystallization and therefore to maintain a constant glass composition in all samples.

Parent glasses were prepared by mixing desired amounts of reagent grade $\mathrm{SiO}_{2}$, $\mathrm{H}_{3} \mathrm{BO}_{3}, \mathrm{Na}_{2} \mathrm{CO}_{3}, \mathrm{Al}_{2} \mathrm{O}_{3}, \mathrm{CaCO}_{3}, \mathrm{MoO}_{3}$ and $\mathrm{Gd}_{2} \mathrm{O}_{3}$. Each batch $(\sim 30 \mathrm{~g})$ was melt at $1500^{\circ} \mathrm{C}$ for $3 \mathrm{~h}$. After a first quenching on a copper plate and grinding, a second melting during $2 \mathrm{~h}$ was made to increase homogeneity. During the first melting, a plateau at $700^{\circ} \mathrm{C}$ during 4 hours was made for decarbonation of $\mathrm{Na}_{2} \mathrm{CO}_{3}$ and $\mathrm{CaCO}_{3}$. Samples are then quenched onto a copper plate and annealed at $500^{\circ} \mathrm{C}$ for $2 \mathrm{~h}$ to relieve internal stresses. Chemical analysis by Energy Dispersive X-ray analysis (EDX) of glasses showed that the final Na content is about $40 \%$ lower after the melting process, other elements contents seemed to be unchanged (boron content was not measured).

\section{Heat treatments}

Two different crystallization methods (see fig.1) were investigated to control size and concentration of powellite phase inside glass-ceramics. Since powellite crystallization is strongly dependent on cooling rates $[9,7]$, all cooling stages are similar and are performed the same way. The nucleation temperature was chosen at $820^{\circ} \mathrm{C}$ according to literature $[15,16$, 17] and data obtained by Differential Thermal Analysis (DTA). The growth temperature was chosen at $1050^{\circ} \mathrm{C}$. 
(i) The first method consists in a long nucleation stage at $820^{\circ} \mathrm{C}$ during $110 \mathrm{~h}$. Samples were introduced in a pre-heated furnace and quenched in air, and then annealed at $500^{\circ} \mathrm{C}$ for $2 \mathrm{~h}$. This heat treatment is labeled $\mathrm{N}$ (for nucleation).

(ii) The second method consists in three stages: a short nucleation phase at $820^{\circ} \mathrm{C}$ during 2 hours followed by a growth stage at $1050^{\circ} \mathrm{C}$ during $20 \mathrm{~h}$ and a long nucleation stage of $112 \mathrm{~h}$. This heat treatment is labeled NG (for nucleationgrowth).

The last nucleation stage of the second method was necessary to reach the same powellite concentration obtained during the first heat treatment. Indeed, since the dissolution temperature is close to the nucleation temperature [18], powellite is dissolved during the growth stage. Samples were annealed at $500^{\circ} \mathrm{C}$ for $2 \mathrm{~h}$.

\section{Samples characterization}

Sample microstructure (morphology and size distribution of powellite phase) was investigated by Scanning Electron Microscopy (SEM). For that purpose, glass slices were polished and $\mathrm{Au}$ coated, micrographs were taken at $(20 \mathrm{kV}, 10 \mu \mathrm{A})$ with a Hitachi s-4800 field emission microscope. Complementary chemical analyses were also performed using Energy Dispersive X-ray (EDX).

X-ray diffraction (XRD) data were collected on powder samples (particle size $\leq 40 \mu \mathrm{m}$ ) at room temperature using a Panalytical (Philips) diffractometer in the Bragg-Brentano geometry with a $\mathrm{Cu}$ anti-cathode: $\mathrm{K} \alpha_{1}(\lambda=1.54560 \AA), \mathrm{K} \alpha_{2}(\lambda=1.54439 \AA),(40 \mathrm{kV}, 40 \mathrm{~mA})$ and a linear detector. The angular range $15^{\circ}-60^{\circ}$ was scanned in $0.02^{\circ}$ steps with a minimum counting time of $90 \mathrm{~s} / \mathrm{step}$. Particular attention was paid to probe the same volume of powder for all samples during XRD measurements for quantification. Indeed, in order to quantify powellite in glass-ceramics, we made and abacus to link the area of powellite XRD peaks between $12^{\circ}$ and $55^{\circ}$ to the molar percentage of powellite in the glass-ceramics. For this purpose, various relative amounts of a Gd-doped powellite, which composition was close to the powellite in glass-ceramics, were mixed with the ideal residual glass (which corresponds to the residual glass if all molybdenum is crystallized into powellite). We checked that preferred orientation biases were very weak. Since there were errors made due to differences in chemical compositions, we checked our results by a second method: quantitative analysis with an internal standard as used in [16] for example. We used chromium oxide as the standard and mixed it with glass-ceramic powder with a ratio of $10 \%$ in mass. The peak area 
is calculated by numerical integration after removal of the Wide Angle X-ray Scattering (WAXS) contribution to XRD patterns attributed to the amorphous phase. The WAXS signal was fitted by a spline function. The analysis of Full Width at Half Maximum (FWHM) XRD peaks was performed on samples Mxg-N and Mxg1-N on XRD patterns with a very long counting time (1600 s/step) to have a good peak resolution. The FWHM was measured on the main peak [112].

\section{Results}

\section{Bulk crystallization}

$X R D$ analysis and powellite quantification:

XRD patterns of glass-ceramics prepared by heat treatment $\mathrm{N}$ are depicted on figure 2. For the two series, powellite was the only phase identified in the bulk except for two samples M15g1-N and M45g1-N. Indeed, two other phases were identified in the bulk: an unknown phase in M15g1-N and apatite rich in gadolinium $\mathrm{Ca}_{2} \mathrm{Gd}_{8} \mathrm{O}_{26} \mathrm{Si}_{6}$ in M45g1-N (JCPDS 00-0280212). Some residual peaks corresponding to surface phases were also identified on two patterns: M35g-N and M45g-N. These peaks correspond to the wollastonite phase $\mathrm{CaSiO}_{3}$ grown from the surface (more details are given later). Surface layers were polished but some surface residuals were left due to the geometry and the small size of the samples. The increase of molybdenum content leads to an increase of powellite XRD peaks area and therefore to the increase of powellite content in the glass-ceramics. Besides, the powellite quantity detected by XRD in the series Mxg1 is lower than in the series Mxg at same molybdenum content.

The same trend is observed for the samples prepared by heat treatment NG. Indeed, only powellite phase was observed in the bulk for all samples even for the sample M45g1-NG. It seems that the stage at $1050^{\circ} \mathrm{C}$ prevents Gd-apatite crystallization in bulk. Nevertheless, the threshold to have powellite crystallization in the bulk (see table 1), is different for the two heat treatments. It seems that for $\left[\mathrm{MoO}_{3}\right]=0.5 \mathrm{~mol} \%$ the growth phase at $1050^{\circ} \mathrm{C}$ blocks the crystallization of powellite needles in the bulk, since no peaks attributed to powellite are observed even for long counting times. In this work, the various heat treatments considered with different cooling rates and growth temperatures always led to powellite crystallization. We can therefore conclude that the glass chemical composition or the heat treatments chosen in this work prevents the sodium molybdates phase crystallization. 
The FWHM evolutions of samples Mxg-N and Mxg1-N are presented on figure 3. The FWHM decreases with increasing the molybdenum content for the two series, except for one sample M15g1-N. It also seems that crystals in the Mxg1-N series are slightly smaller than in the Mxg-N series (for $[\mathrm{Mo}] \geq 2.5 \mathrm{~mol} \%$ ). Using the Scherrer formula, the coherent domain size in the direction perpendicular to the plane [112] can be deduced. This size ranges from around $75 \mathrm{~nm}$ to $140 \mathrm{~nm}$ for the biggest crystals (in M45g-N).

Peak area analysis gives us further information to study the molybdenum and the gadolinium content influences on powellite crystallization. Moreover, the residual glass compositions are important in our study since for one set of glass-ceramics we need a similar residual glass to study the influence of $\beta$-irradiation damages. Indeed, we want to analyze the influence of concentration and size-distribution of powellite on irradiation damages. For the main part of the samples chemical analysis is difficult or even unfeasible since powellite crystals are sub micrometric or too close to one another. Therefore we used quantitative analysis by XRD.

First, we can compare the relative quantity of powellite detectable by X-ray diffraction measurements (see fig. 4(a)). The peak area of as quenched samples and the maximum reachable with the initial Mo content are plotted to illustrate the efficiency of heat treatments used in this work. The peak areas are very similar between the two heat treatments for a given $\mathrm{Gd}_{2} \mathrm{O}_{3}$ content, so we can deduce that the Mo amount left in the residual glass is similar and then that the residual glass compositions are also similar. Indeed, our glass compositions were calculated to have the same residual glass if the same quantity of powellite crystallizes. However, it is obvious that samples with a high content in $\mathrm{Gd}_{2} \mathrm{O}_{3}$ are far less crystallized than samples with less $\mathrm{Gd}_{2} \mathrm{O}_{3}$ for the same heat treatments. This could be explained by an enhanced solubility of molybdenum in glass in presence of Gd. Moreover, measurements on few samples without $\mathrm{Gd}_{2} \mathrm{O}_{3}$ oxide showed the same trend (the peak area is higher than for Mxg and Mxg1 series at same $\left.\left[\mathrm{MoO}_{3}\right]\right)$. Note that the crystallization of Gd-apatite in the bulk of M45g1-N sample had no influence on the powellite quantity measured by XRD, since the peak area is similar to the one measured on the sample M45g1-NG.

Second, using the abacus we can calculate the quantity of Mo left in the residual glass (see fig.4 (b)). This quantity corresponds to the molar percentage of Mo that is not in crystalline powellite detectable by XRD. The error bar was estimated by summing the error due to measurements and the error done in peak area calculation. We can notice that there are differences between the heat treatments and also between the two series of samples. First, there are only slight differences between the two heat treatments, so we can consider that the 
two treatments led to similar residual glass compositions taking into account the error bars. Nevertheless, for samples with low gadolinium content, the quantity of Mo left in the glass decreases when the initial Mo content in the parent glass increases. Whereas, for samples with high Gd content, the quantity of Mo left in the glass increases when the initial Mo content in the parent glass increases. Therefore, we can consider that for a given content of $\mathrm{Gd}_{2} \mathrm{O}_{3}$ the Mo content left in glass is almost constant after heat treatments: 0.7 and $1.5 \mathrm{~mol} \%$ of Mo in residual glasses for samples doped with 0.15 and $1 \mathrm{~mol} \%$ of $\mathrm{Gd}_{2} \mathrm{O}_{3}$, respectively. From this data we can deduce the range in powellite weight percentage in our series and compare it to the theoretical weight percentage reachable (controlled by the initial Mo content since $\mathrm{Ca}$ is in excess). For the highest Mo content $(4.5 \mathrm{~mol} \%)$ the nominal percentage of powellite that can be formed is $13.4 \mathrm{wt} \%$. From the experimental data, the highest quantity of powellite reached is $11.6 \mathrm{wt} \%$ by the sample M45g-N, which is close to the nominal percentage.

\section{Crystal area and distribution:}

SEM micrographs of the glass-ceramics with low $\mathrm{Gd}_{2} \mathrm{O}_{3}$ content are depicted on figure 5. Firstly, the morphology depends on the Mo concentration. Indeed, for $\left[\mathrm{MoO}_{3}\right]=0.5 \mathrm{~mol} \%$ only powellite dendrites were observed, whereas only square-based bipyramids were observed for higher concentrations. These observations are consistent with literature for various glass compositions $[15,19]$.

Then, we can notice sharp differences between the two heat-treated series. For the lower Mo concentration, dendrites are observed on the surface and in the bulk for $\mathrm{N}$ heat treatment, whereas dendrites are only observed on the surface for NG heat treatment. The nucleation treatment leads to a homogeneous crystal size distribution while the nucleationgrowth treatment leads to a wide distribution in crystal sizes. In some samples, powellite crystals tend to agglomerate along lines or in small groups. Indeed, during $\mathrm{N}$ treatment crystals are almost homogeneously distributed in space, whereas crystals tend to form groups or lines during the NG heat treatment. The crystals range in size from $50 \mathrm{~nm}$ to $600 \mathrm{~nm}$ in diameter. The crystal size increases with the molybdenum content as already shown by XRD data.

SEM micrographs of the Mxg1 series are given on figure 6. As for samples with low gadolinium content, powellite crystals were observed in all samples. Besides, needles were observed in the bulk only in the sample M45g1-N (see fig. 6 (c)). EDX measurements showed that these needles are rich in $\mathrm{Ca}, \mathrm{Gd}$, and $\mathrm{Si}$. As showed before, XRD results confirmed the presence of the apatite phase $\mathrm{Ca}_{2} \mathrm{Gd}_{8} \mathrm{O}_{26} \mathrm{Si}_{6}$ in the bulk of M45g1-N sample. In EDX 
measurements, there is a lack of gadolinium compared to the stoechiometric proportions of $\mathrm{Ca}_{2} \mathrm{Gd}_{8} \mathrm{O}_{26} \mathrm{Si}_{6}$, but this could be due to a wrong correction in the quantitative calculation. The area distribution and the trend towards crystals agglomeration is similar to the one observed in Mxg series. The crystals range in size from 125 to $300 \mathrm{~nm}$ in diameter. SEM data gave information on the crystal sizes ranges, but a statistical study was not conducted since the resolution was too low for a lot of samples and the gathering of crystals did not allow the calculation of crystal areas by image processing. Complementary studies by TEM (Transmission Electronic Microscopy) could give more details on the crystal size distributions in samples with low Mo content. Moreover, the crystals range in size seems slightly above the range deduced from XRD data analysis.

The morphology of powellite is the same, whatever the $\mathrm{Gd}_{2} \mathrm{O}_{3}$ content is, for $\left[\mathrm{MoO}_{3}\right]$ $=0.5 \mathrm{~mol} \%$, dendrites are observed; and for $2.5 \leq\left[\mathrm{MoO}_{3}\right] \leq 4.5 \mathrm{~mol} \%$, square-based bipyramids are observed. However, big differences in powellite morphology were seen in the samples with $\left[\mathrm{MoO}_{3}\right]=1.5 \mathrm{~mol} \%$ (see fig. 7). At low gadolinium content, after $\mathrm{N}$ treatment powellite crystals were too small to be observed by SEM, whereas at high content, crossshaped crystals (not dendrites) of few micrometers in length are observed. Important differences were also observed after NG treatment: at low Gd content powellite crystals are mainly bipyramids, while at high content round particles and remaining cross-shaped crystals were observed. A secondary phase was observed in the bulk of the sample M15g1-N (see fig. 7 (c)) which corresponds to the additional phase detected by XRD (see fig. 2, right (a)). The EDX analysis revealed that this phase is rich in $\mathrm{Si}, \mathrm{Ca}$ and $\mathrm{Gd}$ but with a very different stoechiometry than gadolinium apatite in accordance with the XRD pattern.

\section{Surface crystallization}

XRD analysis

XRD patterns of samples with $\left[\mathrm{MoO}_{3}\right]=2.5 \mathrm{~mol} \%$ are depicted on figure 8 , these patterns correspond to powder including the surface layer. The comparison with bulks XRD patterns illustrated on figure 2 , shows the presence of new phases at the sample surface. The surface crystallization depends strongly on the $\mathrm{Gd}_{2} \mathrm{O}_{3}$ content and on the heat treatments. Indeed, at low content two additional phases are identified: cristobalite $\left(\mathrm{SiO}_{2}\right)$ and wollastonite $\left(\mathrm{CaSiO}_{3}\right)$. However, the relative ratio between the two phases is different for the two heat treatments. Wollastonite is the main phase observed after $\mathrm{N}$ heat treatment, whereas cristobalite phase is the main phase observed after NG heat treatment. For samples with high 
content in $\mathrm{Gd}_{2} \mathrm{O}_{3}$, cristobalite was identified for samples of Mxg1-N and Mxg1-NG series whereas an unknown phase was only observed for samples of the Mxg1-N series. A sum up of identified phases by XRD and EDX is given in table 1 .

\section{Crystal growth from the surface}

Secondary phases grown from the surface were observed by SEM. SEM observations and EDX analyses are consistent with XRD results. For samples with low gadolinium content, wollastonite needles, identified by EDX, were only visible on Mxg-N samples (see fig. 9 (a,b and c)). No needles were observed on samples Mxg-NG which could explain the differences in the ratio between wollastonite and cristobalite observed by XRD. The penetration depth of wollastonite needles depends on the $\mathrm{CaO}$ content of parent glasses. The thickness varies from $50 \mu \mathrm{m}$ to $500 \mu \mathrm{m}$ with increasing the $\mathrm{CaO}$ content of parent glasses. Besides, it seems that there is a migration of crystals towards the surface for samples Mxg-NG. This phenomenon cannot be attributed to gravity effects since the same trend was observed on various surfaces, not only on the bottom one.

For Mxg1-N and Mxg1-NG samples, an unknown phase was observed by SEM, the EDX analysis showed that these needles are enriched in $\mathrm{Si}, \mathrm{Ca}$ and $\mathrm{Gd}$. However, the peaks on XRD patterns did not match with the Gd-apatite pattern. Moreover, the needles grew preferentially perpendicular to the surface in Mxg1-N samples, whereas they grew preferentially parallel to the surface in Mxg1-NG samples. Besides, the crystallized layer is much thicker for samples Mxg1-N (around $300 \mu \mathrm{m}$ ) than for samples Mxg1-NG (less than 50 $\mu \mathrm{m})$. Contrary to wollastonite crystallization, the penetration depth of these needles does not depend on the initial $\mathrm{CaO}$ content even if these needles are enriched in calcium. The small surface layer thickness could explain the fact that this phase was not observed on XRD patterns of samples Mxg1-NG.

\section{Discussion}

In this study, we have shown that the borosilicate glass composition and the synthesis protocol led mainly to glass-ceramics containing only the powellite phase in the bulk. Several parameters seem to be involved in this result like cooling rates, heat treatments and parent glass compositions. First, the cooling rate is known to strongly influence the crystallization of molybdate phases $[8,9,16]$. Indeed, it seems that for slow cooling rates sodium molybdates 
can crystallize in the bulk, whereas only powellite crystallizes for higher cooling rates like quenching on a metal plate [9]. Additional phases can however crystallize in the bulk depending on the heat treatment applied and the glass chemical composition. Indeed, we showed that a growth phase at $1050{ }^{\circ} \mathrm{C}$ can prevent apatite crystallization in M45g1-NG bulk (fig. 6 (c) and (e)). Heat treatment optimization can therefore lead to a better control on phase crystallization for a given glass composition. Finally, Caurant et al. [10, 20] showed that the chemical composition of the parent glasses is an important parameter controlling the molybdate phase crystallization. Indeed, these authors showed that high boron contents favor more $\mathrm{CaMoO}_{4}$ than $\mathrm{Na}_{2} \mathrm{MoO}_{4}$ crystallization. Preferential charge compensation of tetrahedral boron units by $\mathrm{Na}^{+}$ions in the glass phase can explained this result as shown by Angeli et al. [21]. The same trend is observed for calcium, since an excess of calcium leads to more powellite crystallization. The aluminum content may also play a role since the $\mathrm{AlO}_{4}$ tetrahedral units are preferentially compensated by $\mathrm{Na}^{+}$cations [22]. In our glass compositions the boron content is quite high and varies from 14.2 to $17.8 \mathrm{~mol} \%$. Moreover the calcium content was increased as the Mo content to keep an high $[\mathrm{CaO}] /([\mathrm{CaO}]+[\mathrm{Na} 2 \mathrm{O}])$ ratio in parent glasses. This ratio is always higher than 0.3 and increases with the Mo content.

The second main result of this work is that the powellite crystallization is limited in quantity and in crystal sizes. Indeed, the powellite content (see fig. 4) reached almost $12 \mathrm{wt} \%$ with $[\mathrm{Mo}]=4.5 \mathrm{~mol} \%$. Higher Mo doping up to $7 \mathrm{~mol} \%$, in a previous work [7] led to phase separation after quenching. The limit was therefore fixed at $4.5 \mathrm{~mol} \%$ in this work to synthesize glass-ceramics without phase separation before crystallization (powellite crystals have facets and do not look like globules, see figure 6 (e) and (f)). This shows that the system studied in this work is limited in quantity of powellite. Changes in the parent glass composition could increase this limit, like decreasing the Gd content. However, the range obtained is sufficient to have contrasts between the samples. The size of powellite crystals is also limited, mainly because the growth temperature is higher than the dissolution temperature as already showed by [15]. This phenomenon is crucial in our study since we need a constant residual glass composition, and so the dissolution of small particles has to be limited during the growth stage. Another barrier is the growth kinetics which was showed by Orlhac et al. to be limited by the volume diffusion of glass species [15]. This means that the size increases with the square root of time and can rapidly reach the maximum in a few tens of hours. In this study the bigger crystals reached around $5 \mu \mathrm{m}$ along the longest direction. Besides, the differences observed in crystal sizes deduced from XRD and SEM data could be due to various reasons. However, no assumption can be favored since no statistical study was 
possible on SEM micrographs and therefore the discrepancy could be an artifact. Moreover the correspondence between the two sizes is not obvious (directions, mean value ...).

We showed finally that the $\mathrm{Gd}_{2} \mathrm{O}_{3}$ content plays a key role on powellite crystallization and on Mo stabilization in the residual glass. The XRD results showed that increasing the amount of $\mathrm{Gd}_{2} \mathrm{O}_{3}$ led to the inhibition of powellite crystallization. This difference in powellite quantity is either observed on as quenched samples or on heat-treated samples. Therefore, differences in nucleation or growth temperatures due to slight differences in chemical compositions of parent glasses cannot explain this phenomenon. As proposed in $[10,7]$, the

presence of $\mathrm{Gd}^{3+}$ ions in the depolymerized regions rich in $\mathrm{MoO}_{4}{ }^{2-}$ species could increase the Mo solubility in the residual glass. The SEM study showed that the morphology at low content in Mo is strongly modified by the rare earth content. The differences mainly observed on samples with $\left[\mathrm{MoO}_{3}\right]=1.5 \mathrm{~mol} \%$ could be explained by the "[ $\left.\mathrm{MoO}_{3}\right]$ available". If we assume that the stabilization of $\mathrm{MoO}_{4}{ }^{2-}$ by $\mathrm{Gd}^{3+}$ ions prevails over powellite crystallization: the Mo available for powellite crystallization is less than the Mo content. Therefore, the crossshaped needles (fig. 7 (c)) observed on M15g1-N may be the intermediate morphology between powellite dendrites (fig. 5 (a)) and bipyramids (fig. 6 (d)). By the same token, the trend of the $\left[\mathrm{MoO}_{3}\right]$ left in residual glasses calculated by XRD quantification can be explained (fig. 4, right). For Mgx samples, if we assume that $\mathrm{Gd}^{3+}$ ions available to stabilize $\mathrm{MoO}_{4}{ }^{2-}$ species are always consumed whatever the Mo content is, then increasing Mo content leads to higher probability to have regions rich in $\mathrm{Ca}$ and Mo. Therefore, when the Mo content increases between 0.5 and $4.5 \mathrm{~mol} \%$ the quantity of crystallized powellite compared to the initial Mo content increases. And that is why we observe a decreasing trend of Mo left in residual glasses with increasing Mo amounts. For Mgx 1 samples, the trend is opposite since the Mo left in residual glasses increases with increasing Mo amounts. From the comparison of crystallization of samples Mxg and Mxg1, we can deduce that Mo solubilization by $\mathrm{Gd}^{3+}$ ions and powellite crystallization are two competitive processes. Since the more molybdenum there is in the glass, the higher the probability to be close to $\mathrm{Gd}^{3+}$ ions and $\mathrm{Ca}^{2+}$ is, we can assume that the stabilization of $\mathrm{MoO}_{4}{ }^{2-}$ species by $\mathrm{Gd}^{3+}$ is favored compared to the crystallization of powellite.

\section{Conclusion}

During this work we studied the influence of Mo and Gd content on powellite crystallization in an alumino-borosilicate glass matrix. Heat treatments were optimized to get 
various powellite crystals sizes and concentrations keeping similar residual glass compositions. Complementary chemical analysis will be performed to probe the molybdenum left in the glass. The range in molybdenum content used in this work showed the limits of the system in terms of powellite concentration and crystal sizes. Indeed, the maximum powellite content reachable without phase separation was around $12 \mathrm{wt} \%$. Moreover, the more efficient heat treatment without powellite dissolution led to crystal sizes under $5 \mu \mathrm{m}$. We showed that $\mathrm{Gd}_{2} \mathrm{O}_{3}$ content has a strong influence both on morphology and on crystallization of powellite by SEM and XRD analysis. It has been shown that $\mathrm{Gd}^{3+}$ ions inhibit powellite crystallization. The most probable reason could be that gadolinium contributes to the stabilization of $\mathrm{MoO}_{4}{ }^{2-}$ units.

The two characterization methods, XRD and SEM, used during this study showed their limits and suggest the use of spectroscopic methods to understand better the $\mathrm{Gd}^{3+}$ ions role in $\mathrm{CaMoO}_{4}$ crystallization and molybdenum solubilization.

\section{Acknowledgements}

The authors would like to acknowledge I. Maurin for the help during XRD measurements.

\section{References}

[1] S. Peuget, J.-N. Cachia, C. Jégou, X. Deschanels, D. Roudil, V. Broudic, J.M. Delaye, and J.-M. Bart, "Irradiation stability of R7T7-type borosilicate glass", J. Nucl. Mater., 354,1-13 (2006).

[2] E.Y. Vernaz and J.L. Dussossoy, "Current state of knowledge of nuclear waste glass corrosion mechanisms: the case of R7T7 glass", Applied Geochemistry, 7,13-22 (1992).

[3] P. Frugier, C. Martin, I. Ribet, T. Advocat, and S. Gin, "The effect of composition on the leaching of three nuclear waste glasses: R7T7, AVM and VRZ”, J. Nucl. Mater, 346, 194-207 (2005).

[4] W.J Weber, R.C Ewing, and A Meldrum, "The kinetics of alpha-decay-induced amorphization in zircon and apatite containing weapons-grade plutonium or other actinides", J. Nucl. Mater, 250, 147-155 (1997).

[5] P. Loiseau, D. Caurant, N. Baffier, L. Mazerolles, and C. Fillet, "Glass-ceramic nuclear waste forms obtained from $\mathrm{SiO}_{2}-\mathrm{Al}_{2} \mathrm{O}_{3}-\mathrm{CaO}-\mathrm{ZrO}_{2}-\mathrm{TiO}_{2}$ glasses containing lanthanides $(\mathrm{Ce}$, $\mathrm{Nd}, \mathrm{Eu}, \mathrm{Gd}, \mathrm{Yb}$ ) and actinides (Th): study of internal crystallisation”, J. Nucl. Mater, 335, 1432 (2004). 
[6] W. Lutze, J. Borchardt, and A. K. Dé, "Characterization of Glass and Glass Ceramic Nuclear Waste Forms"; pp. 69-81 in Scientific Basis for Nuclear Waste Management I, Edited by G. J.McCarthy. Plenum Press, New York, 1979.

[7] T. Taurines and B. Boizot, "Synthesis of powellite-rich glasses for high level waste immobilization", J. Non-Cryst. Solids, STRUCTURE OF NON-CRYSTALLINE MATERIALS 11 Proceedings of the 11th Conference on the Structure of Non-Crystalline Materials (NCM11) Paris, France June 28- July 2, 2010, 357, 2723-2725 (2011).

[8] N. Chouard, D. Caurant, O. Majerus, J.L. Dussossoy, A. Ledieu, S. Peauget, R. BaddourHadjean, and J.-P. Pereira-Ramos, "Effect of neodymium oxide on the solubility of $\mathrm{MoO}_{3}$ in an aluminoborosilicate glass", J. Non-Cryst. Solids, STRUCTURE OF NON-CRYSTALLINE MATERIALS 11 Proceedings of the 11th Conference on the Structure of Non-Crystalline Materials (NCM11) Paris, France June 28-July 2, 2010, 357, 2752-2762 (2011).

[9] M. Magnin. «Etude des processus de demixtion et de cristallisation au sein de liquide fondus borosilicatés riches en oxyde de molybdène ». PhD. thesis, Paris VI, France, 2009.

[10]D. Caurant, O. Majérus, E. Fadel， A. Quintas， C. Gervais， T. Charpentier, and D. Neuville, "Structural investigations of borosilicate glasses containing $\mathrm{MoO}_{3}$ by $\mathrm{MAS}$ NMR and raman spectroscopies", J. Nucl. Mater, 396, 94-101 (2010).

[11] J. de Bonfils, G. Panczer, D. de Ligny, S. Peuget, and B. Champagnon, «Behaviour of simplified nuclear waste glasses under gold ions implantation: A microluminescence study", J. Nucl. Mater, 362, 480-484 (2007), E-MRS 2006: Symposium N.

[12] Bruno Boizot, Nadège Ollier, Florent Olivier, Guillaume Petite, Dominique Ghaleb, and Euguenia Malchukova. "Irradiation effects in simplified nuclear waste glasses", Nuclear Instruments and Methods in Physics Research Section B: Beam Interactions with Materials and Atoms, 240, 146-151 (2005) in Accelerators in Applied Research and Technology Proceedings of the Eighth European Conference on Accelerators in Applied Research and Technology (ECAART-8).

[13] B. Boizot, G. Petite, D. Ghaleb, B. Reynard, and G. Calas, "Raman study of $\beta$ irradiated glasses", J. Non-Cryst. Solids, 243, 268-272 (1999).

[14] N. Ollier, G. Rizza, B. Boizot, and G. Petite, "Effects of temperature and flux on oxygen bubble formation in $\mathrm{Li}$ borosilicate glass under electron beam irradiation", J. Appl. Phys., 7,73511 (2006).

[15] X. Orlhac, C. Fillet, and J. Phalipou, "Study of crystallization mechanisms in the French nuclear waste glass”, Mat. Res. Soc. Symp. Proc., 556, 263-270 (1999). 
[16] N. Henry, P. Deniard, S. Jobis, R. Brec, C. Fillet, F. Bart, A. Grandjean, and O. Pinet, "Heat treatment versus microstructure in molybdenum-rich borosilicate", J. Non-Cryst. Solids, 333, 199-205 (2004).

[17] C. Mendoza, "Caractérisation et comportement sous irradiation de phases powellites dopées terres rares - Application au comportement à long terme des matrices de confinement des déchets nucléaires" ; PhD. thesis, Université Claude Bernard - Lyon 1, France, 2010.

[18] X. Orlhac, "Etude de la stabilité thermique du verre nucléaire. Modélisation de son évolution à long terme"; Ph.D. thesis, University of Montpellier II, France, 1999.

[19] N. Chouard, N. Guezi-Hasni, D. Caurant, O. Majerus, J.L. Dussossoy, and A. Ledieu, "Impact des conditions de traitements thermiques sur la cristallisation dans un verre nucléaire simplifié ", in Matériaux 2010 meeting, France, 2010.

[20] D. Caurant, O. Majerus, E. Fadel, and M. Lenoir, "Effect of molybdenum on the structure and on the crystallization of $\mathrm{SiO}_{2}-\mathrm{Na}_{2} \mathrm{O}-\mathrm{CaO}-\mathrm{B}_{2} \mathrm{O}_{3}$ ”, J. Am. Ceram. Soc., 90, 774783 (2007).

[21] F. Angeli, T. Charpentier, D. De Ligny, and C. Cailleteau, «Boron speciation in sodalime borosilicate glasses containing zirconium", J. Am. Ceram. Soc., 93, 2693-2704 (2010).

[22] A. Quintas, D. Caurant, O. Majerus, T. Charpentier, and J.L. Dussossoy "Effect of compositional variations on charge compensation of $a o_{4}$ and $b o_{4}$ entities and on crystallization tendency of rare-earth-rich aluminoborosilicate glass", MRS Bull., 44, 18951898 (2009). 
Table 1

\begin{tabular}{|c|c|c|c|c|}
\hline Set & $\begin{array}{c}\text { Mo } \\
\text { threshold }{ }^{1}\end{array}$ & Morphology of bulk powellite & Phase in bulk ${ }^{2}$ & Phase on the surface ${ }^{2}$ \\
\hline Mxg-N & $0.5 \mathrm{~mol} \%$ & $\begin{array}{c}{\left[\mathrm{MoO}_{3}\right]=0.5 \mathrm{~mol} \% \text { dendrites }} \\
{\left[\mathrm{MoO}_{3}\right] \geq 1.5 \mathrm{~mol} \% \text { bipyramids }}\end{array}$ & powellite & $\begin{array}{l}\text { Wollastonite ++ } \\
\text { Cristobalite + }\end{array}$ \\
\hline $\begin{array}{c}\text { Mxg- } \\
\text { NG }\end{array}$ & $1.5 \mathrm{~mol} \%$ & {$\left[\mathrm{MoO}_{3}\right] \geq 1.5 \mathrm{~mol} \%$ bipyramids } & powellite & $\begin{array}{l}\text { Cristobalite ++ } \\
\text { Wollastonite + }\end{array}$ \\
\hline Mxg1-N & $0.5 \mathrm{~mol} \%$ & $\begin{aligned} & {\left[\mathrm{MoO}_{3}\right]=} 0.5 \mathrm{~mol} \% \text { unobserved } \\
& {\left[\mathrm{MoO}_{3}\right]=} 1.5 \text { mol\% cross-shaped } \\
& \text { needles }\end{aligned}$ & $\begin{array}{c}{\left[\mathrm{MoO}_{3}\right]=1.5 \mathrm{~mol} \% \text { powellite, unknown }} \\
\text { phase rich in } \mathrm{Si}, \mathrm{Ca} \text { and } \mathrm{Gd}^{3} \\
{\left[\mathrm{MoO}_{3}\right] \leq 3.5 \mathrm{~mol} \% \text { powellite }} \\
{\left[\mathrm{MoO}_{3}\right]=4.5 \mathrm{~mol} \% \text { powellite, apatite }}\end{array}$ & $\begin{array}{l}\text { Unknown phase rich in } \mathrm{Si}, \\
\mathrm{Ca} \text { and } \mathrm{Gd}^{3}++ \\
\text { Cristobalite }+\end{array}$ \\
\hline $\begin{array}{c}\text { Mxg1- } \\
\text { NG }\end{array}$ & $1.5 \mathrm{~mol} \%$ & $\begin{array}{c}{\left[\mathrm{MoO}_{3}\right]=1.5 \mathrm{~mol} \% \text { cross-shaped }} \\
\text { needles and globules } \\
{\left[\mathrm{MoO}_{3}\right] \geq 2.5 \mathrm{~mol} \% \text { bipyramids }}\end{array}$ & powellite & $\begin{array}{c}\text { Cristobalite }++ \\
\text { Unknown phase rich in } \mathrm{Si} \text {, } \\
\mathrm{Ca} \text { and } \mathrm{Gd}^{3}+\end{array}$ \\
\hline
\end{tabular}

,+++ qualitative relative quantity deduced from XRD patterns

${ }^{1}$ Minimum Mo content in parent glasses to detect powellite either by XRD, MEB or Raman spectroscopy in bulk. ${ }^{2}$ samples probed by XRD and Raman spectroscopy and observed by SEM. ${ }^{3}$ phase different than $\mathrm{Gd}$ apatite $\left(\mathrm{Ca}_{2} \mathrm{Gd}_{8} \mathrm{O}_{26} \mathrm{Si}_{6}\right)$ 
Figure Captions

Fig 1: Schemes $\mathrm{T}=\mathrm{f}$ (time) showing the stages of the two heat treatments used for glassceramics preparation. All quenching phases were made into air, except after annealing (natural decrease of the furnace temperature).

Fig 2: XRD patterns of glass-ceramic bulks. Left: M15g-N (a), M25g-N (b), M35g-N (c), M45g-N (d); right: M15g1-N (a), M25g1-N (b), M35g1-N (c), M45g1-N (d). W: wollastonite; A: apatite; *: unknown phase. Non indexed peaks are attributed to powellite.

Fig 3: FWHM of the main powellite peak $\left(\mathrm{Cu}, 2 \theta=28^{\circ}\right)$ of samples Mxg-N (solid line) and Mxg1-N (dotted lines).

Fig 4: Left : peak area calculated from XRD patterns from $15^{\circ}$ to $55^{\circ}$ for glass-ceramics. Solid lines correspond to samples with low content in $\mathrm{Gd}_{2} \mathrm{O}_{3}$, dotted lines correspond to samples with high content in $\mathrm{Gd}_{2} \mathrm{O}_{3}$. The dashed line is the maximum area reachable with the Mo available in parent glasses. Right: molybdenum content left in the residual glass.

Fig 5: Back-scattered SEM micrographs of glass-ceramics prepared by heat treatment N: M05g-N (a), M35g-N (b), M45g-N (c) and heat treatment NG: M05g-NG surface (d), M35gNG (e), M45g-NG (f). Magnification is the same one for all images.

Fig 6: Back-scattered SEM micrographs of glass-ceramics prepared by heat treatment N: M15g1-N (a), M35g1-N (b), M45g1-N (c) and heat treatment NG: M35g1-NG (d), M45g1NG (e). A: $\mathrm{Ca}_{2} \mathrm{Gd}_{8} \mathrm{O}_{26} \mathrm{Si}_{6}$ apatite

Fig 7: Back-scattered SEM micrographs of glass-ceramics. At low $\mathrm{Gd}_{2} \mathrm{O}_{3}$ content: $\mathrm{M} 15 \mathrm{~g}-\mathrm{N}$ (a), M15g-NG (b). At high $\mathrm{Gd}_{2} \mathrm{O}_{3}$ content M15g1-N (c), M15g1-NG (d). * unknown phase enriched in $\mathrm{Si}, \mathrm{Ca}$ and $\mathrm{Gd}$.

Fig 8: XRD patterns of glass-ceramic bulks and surfaces. M25g-N (a), M25g-NG (b), M25g1$\mathrm{N}$ (c), M25g1-NG (d). W: wollastonite; C: cristobalite; * unknown phase. Non indexed peaks are attributed to powellite.

Fig 9: SEM micrographs of glass-ceramics surfaces, M0g-N (a), M35g-N (b), M15g-NG (c), M05g1-N (d), M35g1-NG (e), M45g1-NG (f). The picture (f) is taken on a tilted sample, the circled surface is the surface in contact with the platinum foil during heat treatment. 
Figures

Fig 1
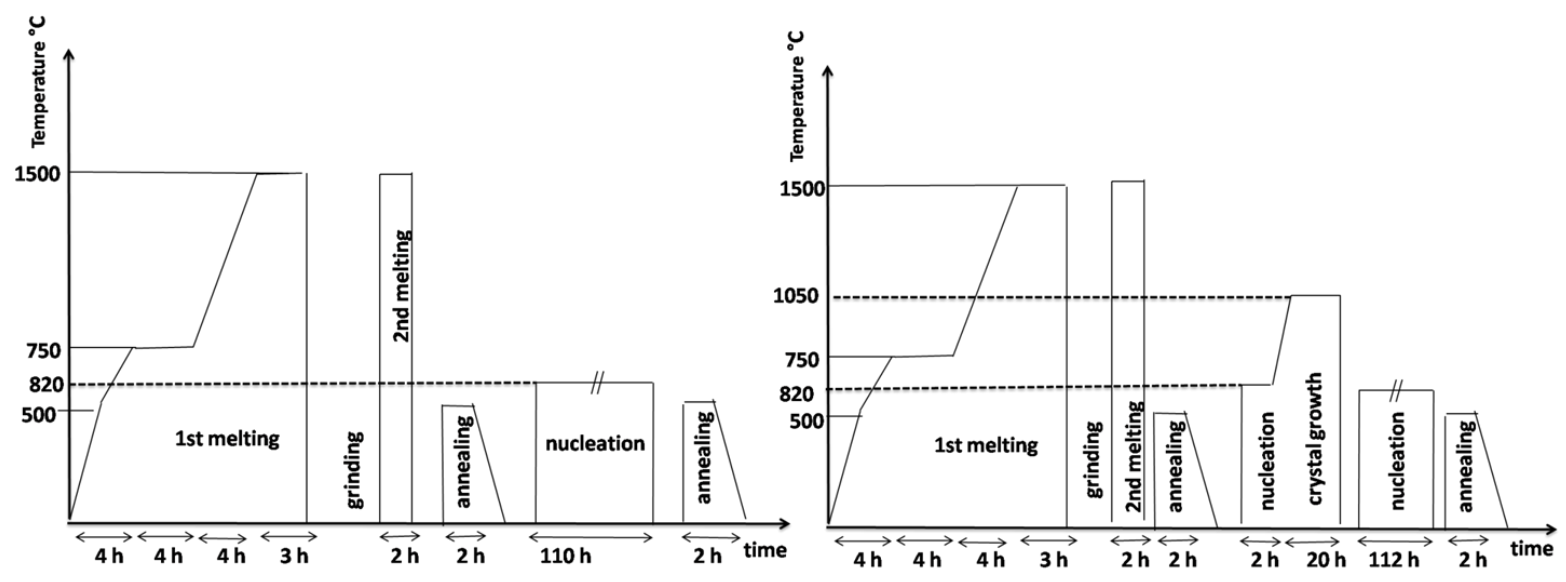
Fig 2
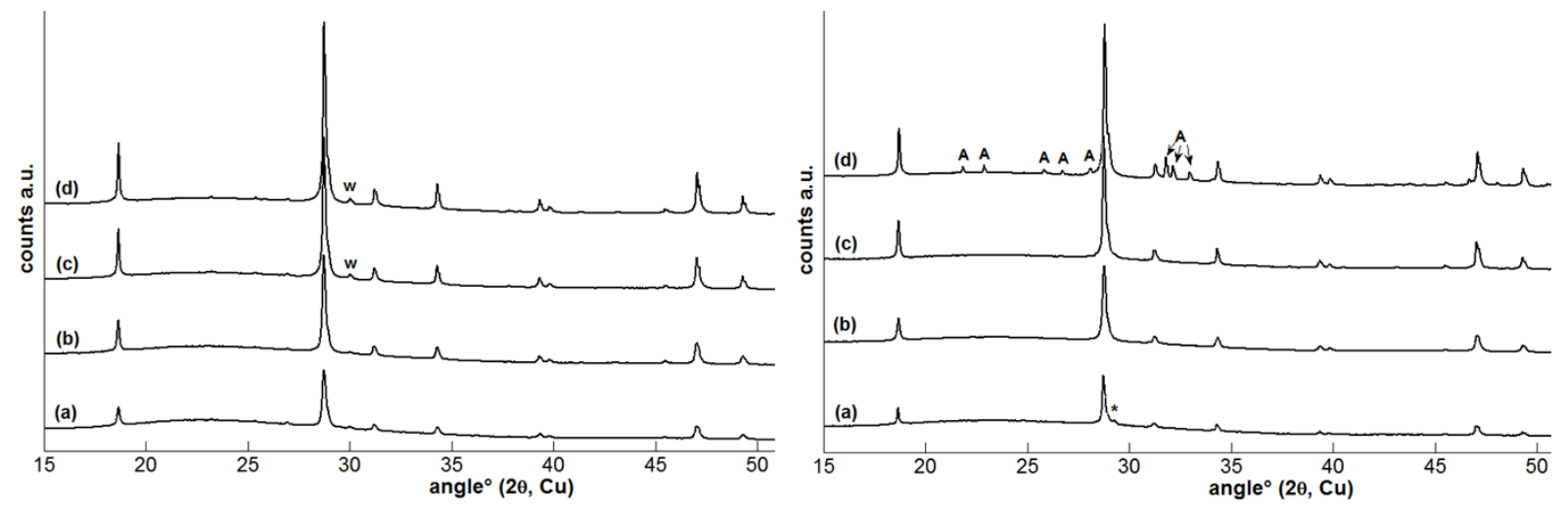
Fig 3

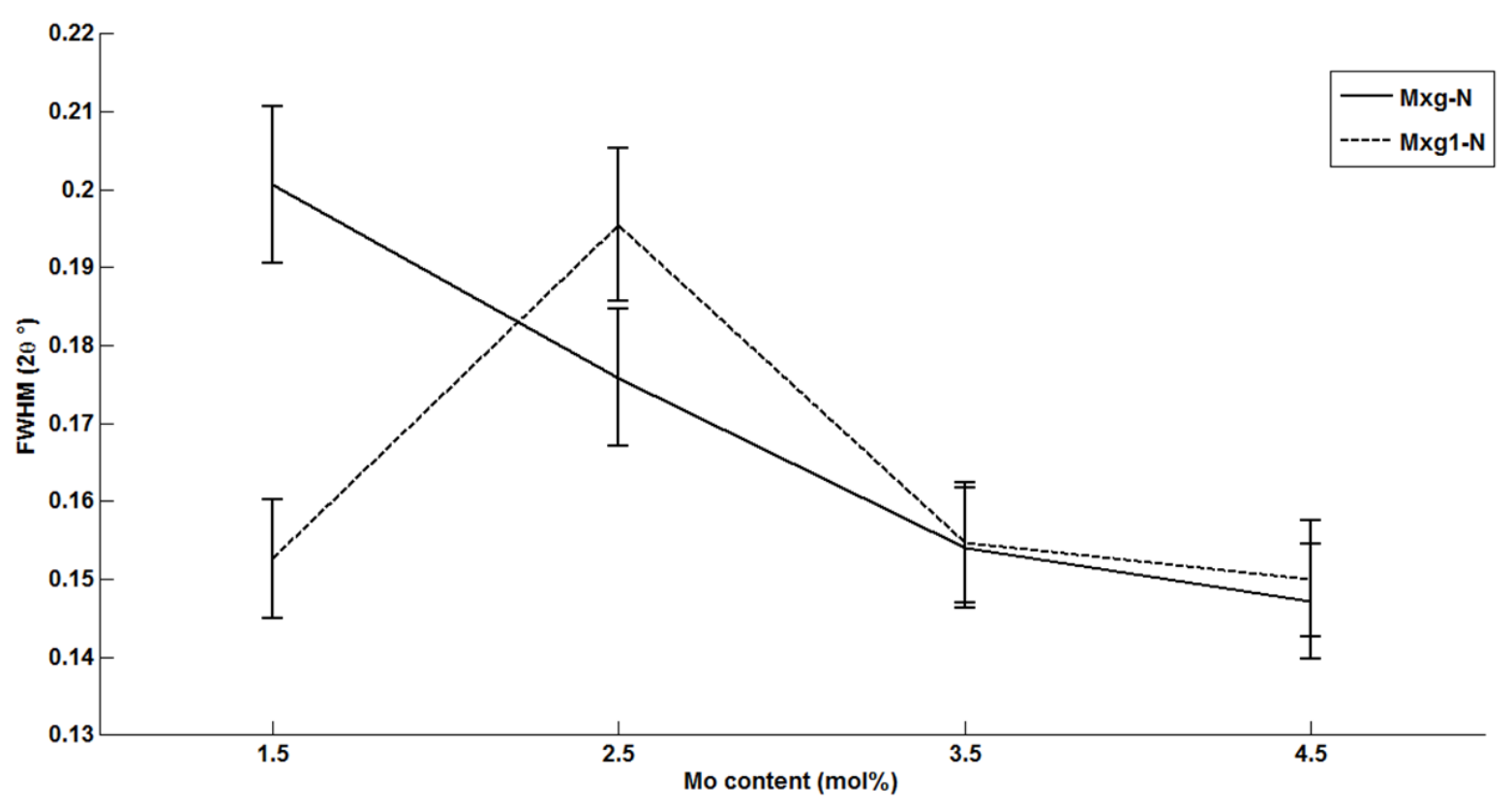


Fig4
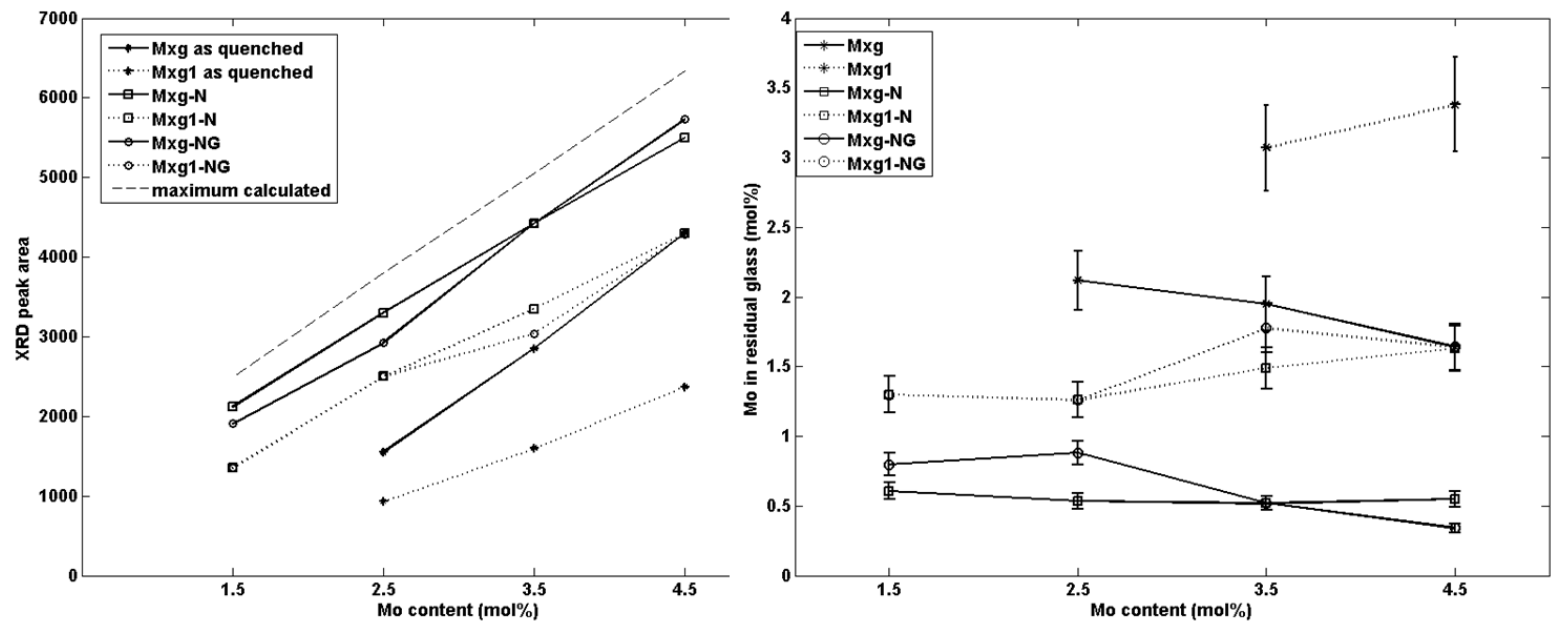
Fig 5
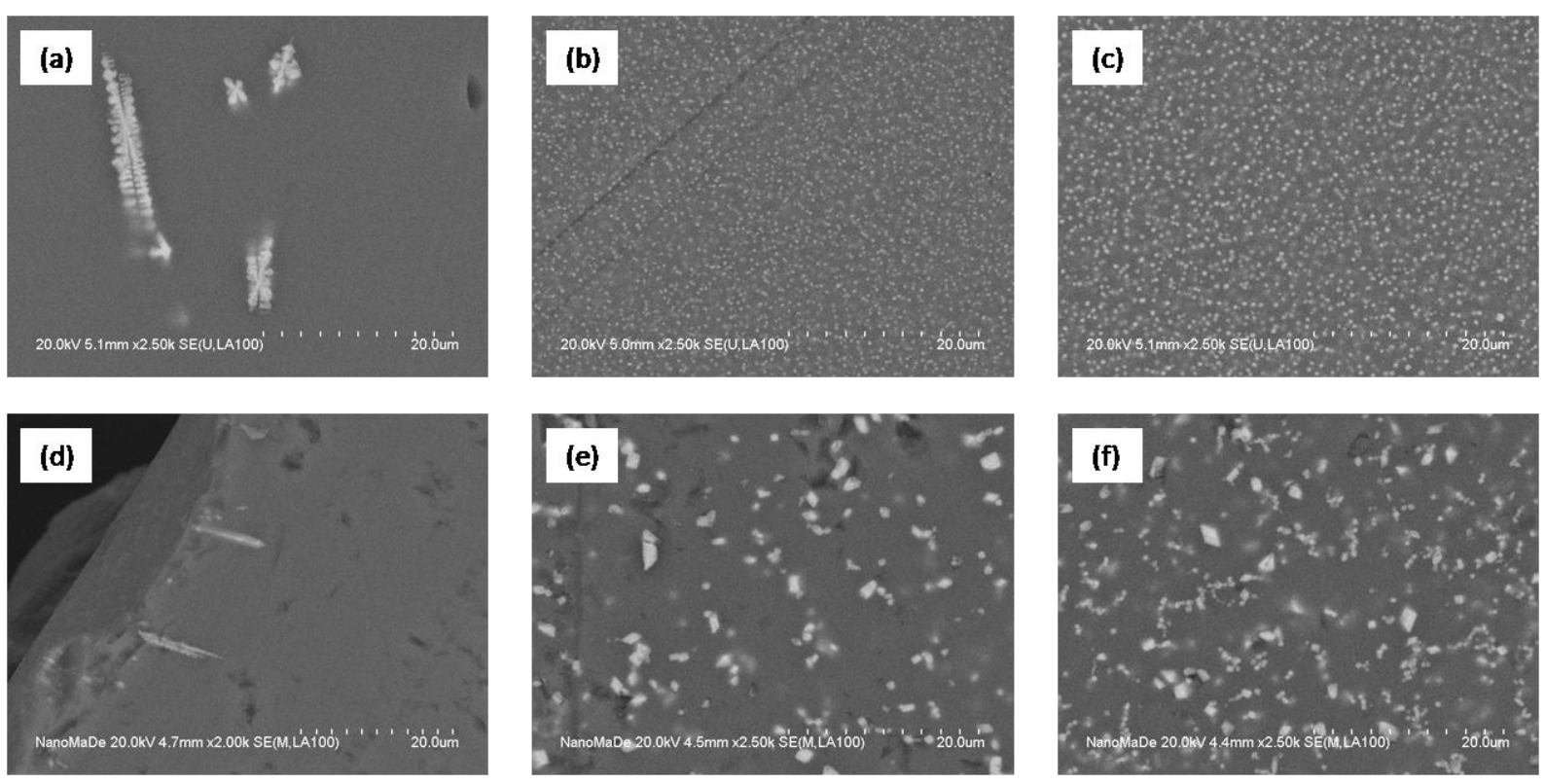
Fig 6
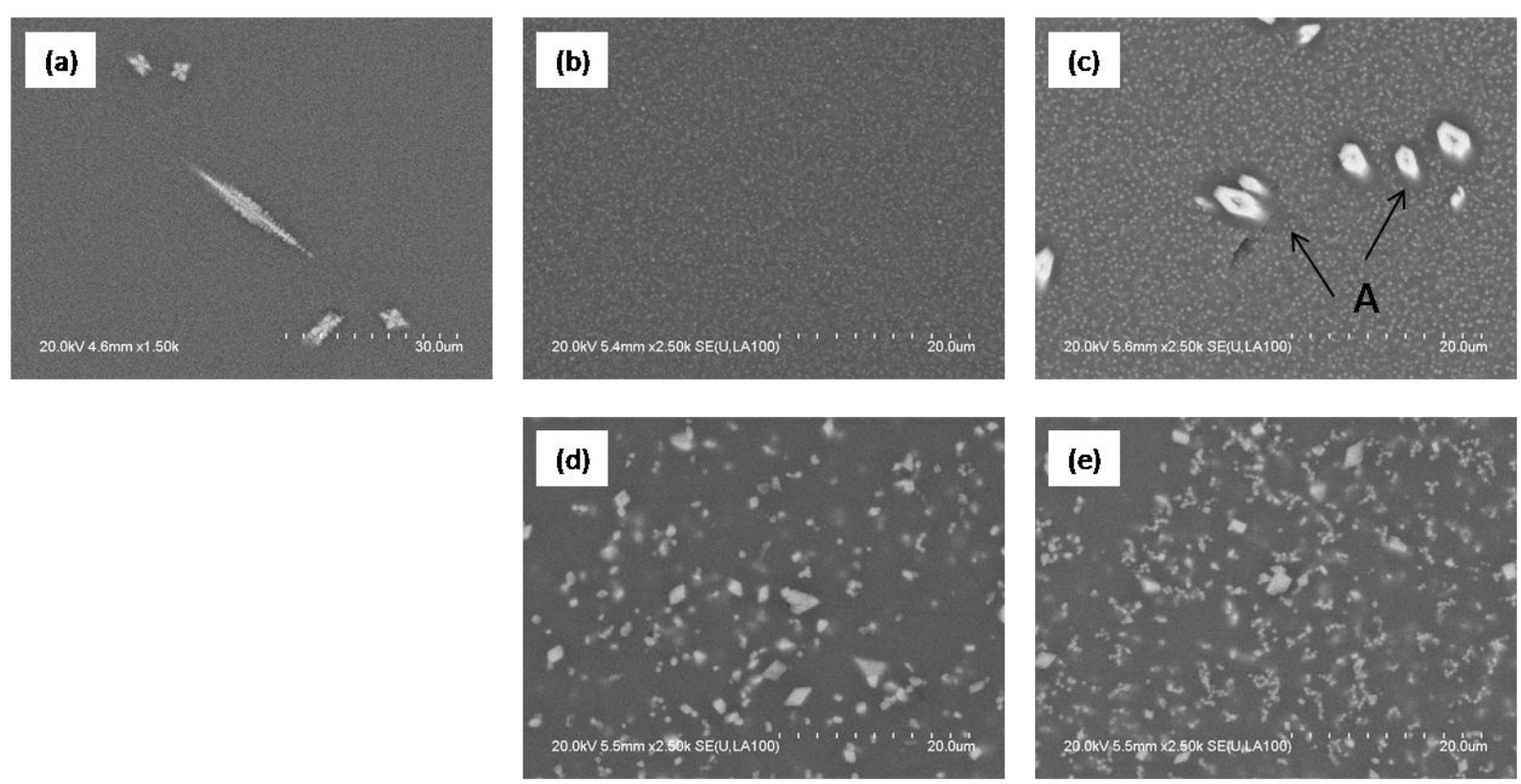
Fig 7
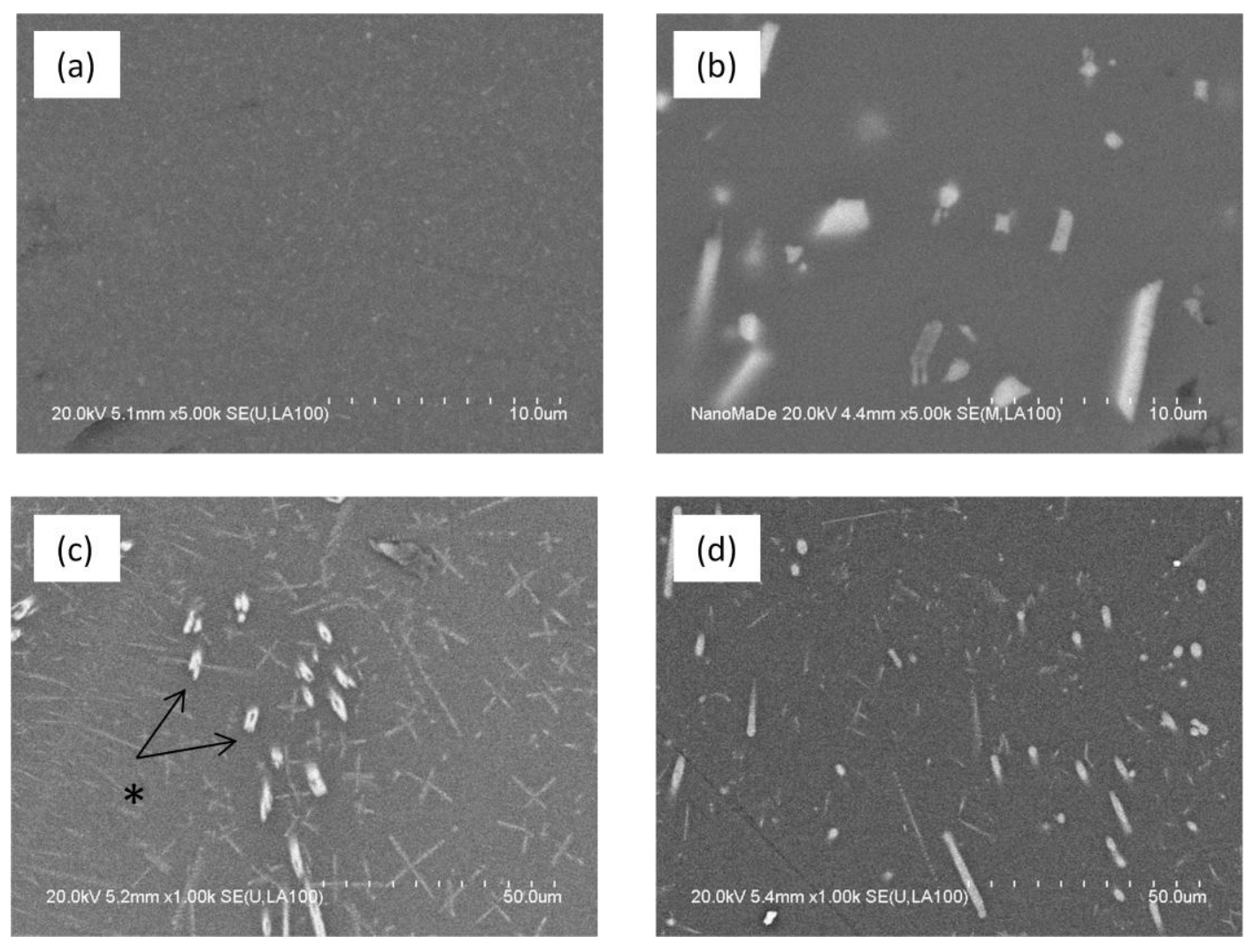
Fig 8

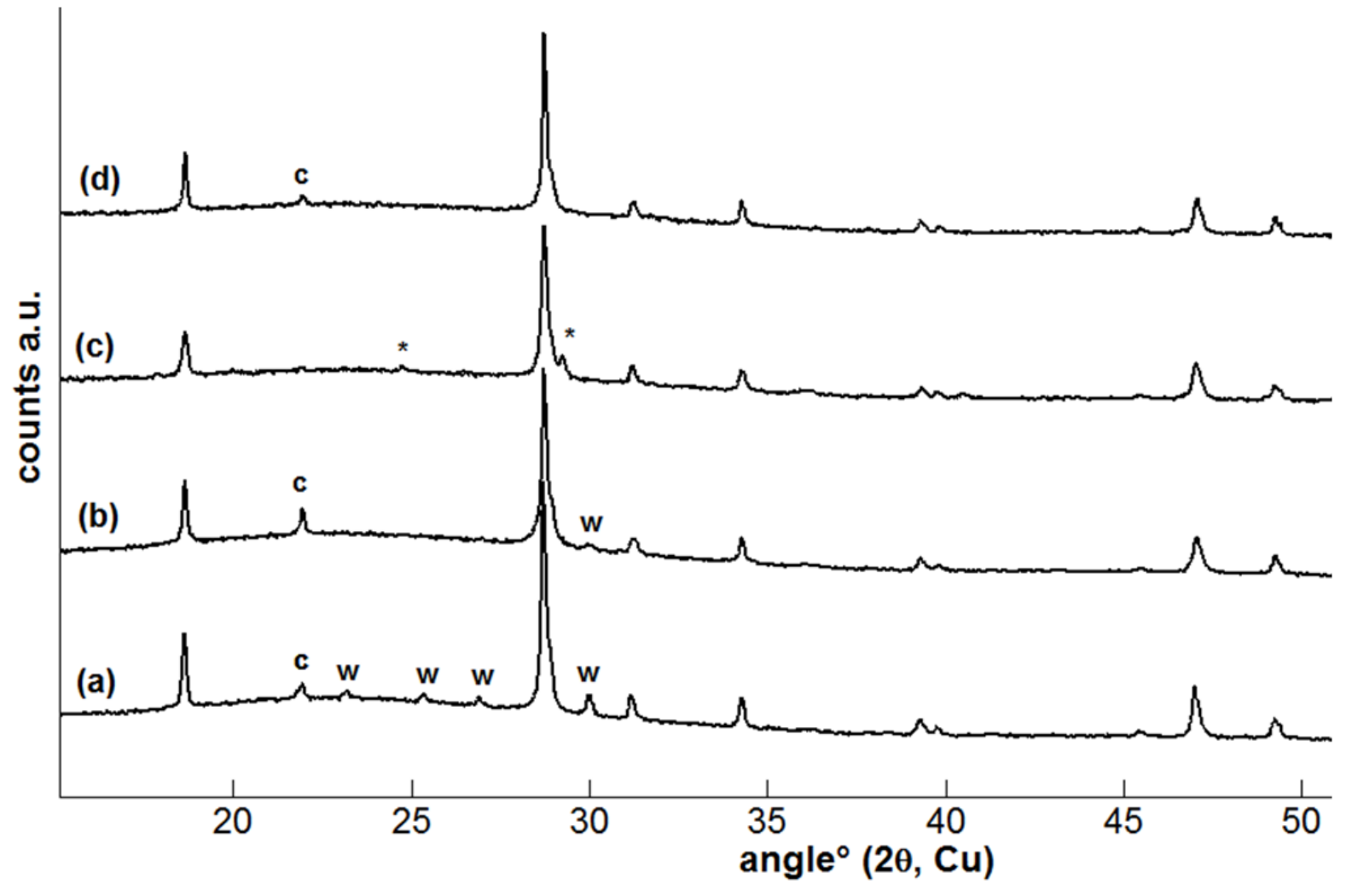


Fig 9
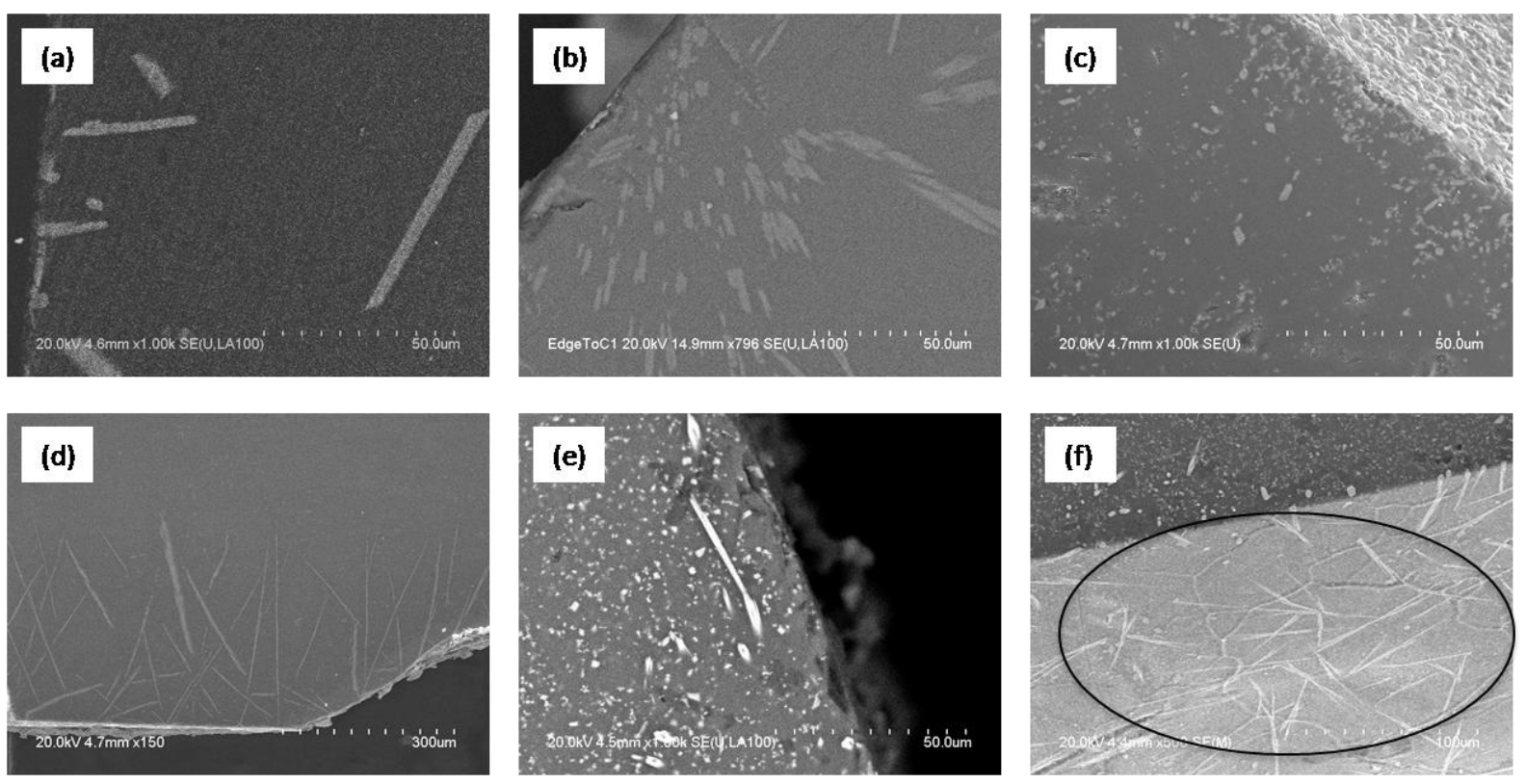
